Bio-grafía. Escritos sobre la Biología y su Enseñanza. ISSN 2027-1034

Número Extraordinario. p.p. 309-316

Memorias del Primer encuentro ambiental Universidad, ambiente y sustentabilidad: experiencias y prácticas.

\title{
BODYWAY: ESTEREOTIPOS DE BELLEZA EN LA ESCUELA; INCIDENCIA DE LOS MEDIOS Y REPERCUSIÓN EN LOS CONTEXTOS
}

\author{
Rondón, Diego. \\ Ardila, V., Barrantes, L., Fuentes, L, González, C., Mateus, J., Peláez, P., \\ Reyes, A., Rincón, N., Rivera, J., Rojas, K., \& Velandia, H. ${ }^{2}$
}

\section{Resumen}

Desde los planteamientos de la investigación como estrategia pedagógica (IEP) de Mejía y Manjarrés (2012) se enmarcan múltiples análisis para efecto de la organización de nuevos proyectos curriculares de ciencias en general y de la enseñanza de la química en particular; a partir de lo cual se pretenden aportar al fortalecimiento y flexibilidad de la enseñanza de las ciencias desde una perspectiva investigativa en el marco de la educación en ciencias para la sustentabilidad, que permita la relación de elementos que caracterizan la dimensión y complejidad química en los distintos ambientes de formación, mediante la inclusión de aspectos de relevancia, en pro de generar y desarrollar procesos más consecuentes relacionados con el contexto social, y cultural de los estudiantes.

Partiendo de lo anterior en el espacio del CLUB DE CIENCIAS DECONSTRUYENDO CONOCIMIENTO AMBIENTAL, se plantea como forma de mejorar los procesos de enseñanza, la relacion de los aspectos teoricos con las problematicas de la vida diaria, esto mediante la autoreflexion por parte de quienes participan en las situaciones sociales de enseñanza, con el fin de mejorar la racionalidad sus propias practicas educativas y su comprension sobre las mismas, ademas de una construccion social desde las diversas situaciones en las instituciones en que estas practicas se realizan. A partir de lo anterior se procedió a diseñar una propuesta metodológica de para realizar una investigación que permite evidenciar la incidencia que tienen los medios de comunicación masivos en los estereotipos de belleza que poseen las personas, y a su vez como se ven permeados mediante los procesos formativos y la edad de los individuos.

${ }^{1}$ Docentes Líder Club de Ciencias Deconstruyendo Conocimiento Ambiental,

drondon.quimica@gmail.com

${ }^{2}$ Estudiantes Club de Ciencias Deconstruyendo Conocimiento Ambiental - L.P.S.J. 
Bio-grafía. Escritos sobre la Biología y su Enseñanza. ISSN 2027-1034

Número Extraordinario. p.p. 309-316

\begin{abstract}
Memorias del Primer encuentro ambiental Universidad, ambiente y sustentabilidad: experiencias y prácticas.
\end{abstract}

Palabras Clave: Estereotipos de Belleza, Sustentabilidad, Relación Ser Humano Ambiente.

\title{
Abstract
}

From research approaches as a pedagogical strategy (IEP) of Mejia and Manjarrés (2012) to effect multiple analyzes of the organization of new curriculum projects general science and chemistry teaching in particular fall; from which are intended to contribute to the strengthening and flexibility of teaching science from a research perspective in the context of science education for sustainability, which allows the relation of elements that characterize the size and chemical complexity in different training environments, by including aspects of relevance, pro-create and develop more consistent processes related to social, and cultural development of students.

Based on the above in space science club deconstructing environmental awareness, it is proposed to improve the teaching, the relationship between the theoretical aspects with the problems of daily life, this by self-reflection by those involved in social teaching situations, to improve their own educational practices rationality and understanding about them, plus a social construction from the diverse situations in the institutions in which these practices are carried out. From the above we proceeded to design a methodological proposal to conduct research that makes evident the incidence of the mass media stereotypes of beauty that people have, and in turn as they are permeated by training processes and age of individuals

Keywords: Beauty Stereotypes, Sustainability, Human - Environment relationship.

\section{INTRODUCCIÓN}

Rondón \& Gil (2015) proponen que los denominados "clubes de ciencias" son como un grupo de personas más motivado por profundizar en intereses personales, que se reúne en tiempos determinados, siendo esto una transformación del conocimiento científico en el aula en pro de la comunidad. Esto brinda un espacio para salirse de la rigidez del aula, para desarrollar un entorno para el debate, intercambiar ideas, reunirse en torno a lectura, se problematiza, se duda, se busca, se cuestiona el mundo que los 
Bio-grafía. Escritos sobre la Biología y su Enseñanza. ISSN 2027-1034

\author{
Número Extraordinario. p.p. 309-316 \\ Memorias del Primer encuentro ambiental Universidad, ambiente y \\ sustentabilidad: experiencias y prácticas.
}

rodea desde ámbitos científicos, axiológicos, culturales y sociales, pero en especial en la búsqueda de comunidad (Mancuso, Lima y Bandeira, 1996).

De lo anterior se evidencia que las temáticas abordadas en el aula de clase se representan en la vida diaria, y es necesario sensibilizar entorno a que es lo que usamos y llevamos a nuestro organismo; debido a que mediante estas experiencias se aprenden aspectos fundamentales básicos en la enseñanza de la química pero importantes para la vida cotidiana, cambiando el paradigma tradicionalista en donde la clase química es la de dictar y copiar, y convirtiéndose en un espacio donde las estudiantes realizan la clase, y se comprende la importancia de la enseñanza de la ciencia reconociendo la funcionalidad en específico de la temática de la formulación química. Por lo tanto, el Club de Ciencia podría representar un enlace perdido entre la escuela y la comunidad, ya que se centralizan en características e intereses de los estudiantes (Longhi y Edson, 2012).

Partiendo de esto y como plantea Mejía y Manjarres (2012) se desarrolla lo que se conoce como investigación como estrategia pedagógica, mediante la implementación de una pregunta como punto de partida, la cual surge de un aprendizaje colaborativo desde las experiencias e intereses vinculados al universo inmediato de los sujetos, quienes relacionan y fundamentan el conocimiento científico con los aspectos de la cultura y vida, actuando en los procesos educativos en conjunto con el maestro como investigadores que reflexionan desde sus diversas perspectivas, que permiten desarrollar la investigación como un elemento constructivo de las transformaciones sociales cambiando de este modo los paradigmas de las tradiciones educativas, siendo allí donde el educador pone en escena su capacidad humana al servicio de intereses precisos y concretos (Rondon \& Gil, 2015).

Respecto a lo anterior se plantea una relación ser humano - ambiente, que en términos Sauvé citada por Rondón \& Gil en 2015, se debe propender por modelo un educacional, encaminado en la sustentabilidad como opción de vida, permitiendo una conexión armónica entre un sistema político, económico, tecnológico, científico, social y cultural en pro de la preservación del ambiente, por tal razón, este eje se plantea en el desarrollo de la propuesta para analizar una verdadera incidencia en las estudiantes acerca de su relación con el ambiente, siendo esto fundamental en la apropiación de la Educación en Ciencias para la Sustentabilidad 
Bio-grafía. Escritos sobre la Biología y su Enseñanza. ISSN 2027-1034

Número Extraordinario. p.p. 309-316

Memorias del Primer encuentro ambiental Universidad, ambiente y sustentabilidad: experiencias y prácticas.

\section{OBJETIVO GENERAL}

- Identificar los imaginarios de belleza que posee la población y como estos se ven influenciados por los medios de comunicación masivos

\section{OBJETIVOS ESPECÍFICOS}

- Conocer que concepción de belleza se presenta en la población participe del taller

- Caracterizar la incidencia que tienen de los medios de comunicación en los estereotipos de belleza

- Como los contextos se ven permeados por las dinámicas de relación entre el ser humano y el ambiente.

\section{METODOLOGÍA}

La enseñanza de las ciencias de estar encaminada a permitir una relación del conocimiento científico con encuentra en cada una de las situaciones que se viven a diario, contribuyendo de este modo al desarrollo integral de la persona ya que promueve actitudes y hábitos intelectuales de gran valor en la sociedad actual, que facilitan a su vez la comprensión de fenómenos socioculturales que tienen lugar en el contexto inmediato de los individuos, ayudando a interpretar de forma racional la realidad y promueve actitudes críticas frente a hechos político-sociales (Rondón, D., 2015).

\section{Desarrollo Metodológico}

A continuación, se enuncian una serie de actividades relacionadas con la dimensión investigativa, que propende por reconocer los imaginarios y perspectivas que posee la población educativa sobre los estereotipos de belleza que infunden los medios de comunicación masivos, y a su vez como estos se van modificando con relación al contexto (población, edad y nivel formativo).

Nombre: BODYWAY, nombre que se le da al taller haciendo alusión a la marca comercial de SUBWAY, generando una comparación que en ambos casos se "seleccionan ingredientes" en relacionan los gustos personales por características físicas, permitiendo de este modo la reflexión frente al cuerpo y la violencia contra del ser humano.

Actividad No.1: Contextualización. Se realizará la presentación del espacio de club de ciencia indicando la finalidad del mismo; seguido se 
Bio-grafía. Escritos sobre la Biología y su Enseñanza. ISSN 2027-1034

Número Extraordinario. p.p. 309-316

Memorias del Primer encuentro ambiental Universidad, ambiente y sustentabilidad: experiencias y prácticas.

indicará en que consiste el taller "BODYWAY", y las instrucciones necesarias para el desarrollo de las actividades programadas. (Materiales: Video Beam)

Actividad No.2: ¡Gana por la perfección! Para este aparto se realizará la presentación de imágenes relacionadas con la belleza desde los medios de comunicación masivos en comparación con representaciones de belleza de algunas etnias o con "personas del común"; de lo cual se espera identificar una tendencia en el imaginario de belleza. Al momento de presentar la comparación de imágenes cada una tiene un color respectivo (RojoAmarillo), al cual se le asignará un valor económico que podrá utilizar en la etapa No.3. (Materiales: Video Beam)

Actividad No.3: BODYWAY. El Bodyway tiene como propósito el saber cuál es el prototipo de belleza que la sociedad a impuesto de diferentes maneras, mediante la incidencia de los medios de comunicación, a su vez la relación entre la persona con su prototipo de "mujer u hombre ideal"; esto mediante la selección de partes del cuerpo (formas de boca, nariz, tamaños de senos, contextura corporal, color de piel y ojos, tipo de cabello, entre otros) que consideran deben llevar el "prototipo humano ideal". (Materiales: Video Beam)

Actividad No.4 Reflexión en torno a videos Esta actividad tiene como propósito contextualizar y sensibilizar mediante una problemática la importancia del conocimiento científico, para este caso la incidencia de los medios de comunicación masivos mediante el uso de dos videos (Dollface y Supervenus), que permitirán apoyar el desarrollo del taller. (Materiales: Video Beam)

Actividad No.5 Reflexión final. Esta dinámica presenta un apoyo lúdico, mediante el uso de una "lana" que se usa para formar una red a medida que las estudiantes van participando de la discusión alrededor de los videos y las preguntas orientadoras de la lectura, para concluir el debate, apoyado en preguntas orientadoras y de forma simbólica se recoge la lana como finalización y sensibilización de la actividad. (Materiales: Video Beam Instrumento semiestructurado) 


\title{
Bio-grafía. Escritos sobre la Biología y su Enseñanza. ISSN 2027-1034
}

Número Extraordinario. p.p. 309-316

\begin{abstract}
Memorias del Primer encuentro ambiental Universidad, ambiente y sustentabilidad: experiencias y prácticas.
\end{abstract}

\section{REFLEXIONES FINALES}

Este tipo de propuestas metodológicas, permite una reflexión e indagación de las perspectivas de belleza que posee la sociedad y la incidencia que estas tienen desde los medios masivos de comunicación. Partiendo de esto se plantea el hecho que la escuela en términos de Rondón \& Gil en 2015 es un proyecto de comunidad, el cual se involucra en un entorno vivo compartido, donde se prioriza el foco del análisis sociocrítico relacionado con la preocupación política para la comunidad en pro de un sistema que se encuentra en equilibrio entre lo económico, cultural, social y ecológico.

Propendiendo por un aprendizaje de carácter lúdico recreativo, que permite una reflexión en torno a las dinámicas socio culturales, de los contexto inmediatos en los cuales se desenvuelven los individuos del Club de Ciencias Deconstruyendo Conocimiento Ambiental, justificando de este modo lo que plantea Mejía y Manjarres citado por Rondón \& Gil en 2015, donde se plantea la necesidad de desarrollar la capacidad de ir más allá de los comportamientos esperados, partiendo de la curiosidad crítica del sujeto sin la cual se dificultan la invención y la reinvención de las cosas.

Además desde lo anterior reconocer que los currículos de ciencia que se presentan en la mayoría de instituciones educativas del país abordan la ciencia de una forma tradicional que lleva a dinámicas de una transmisiónrecepción imprecisa de conceptos científicos, esto debido a la falta de involucrar el contexto de los estudiantes en los procesos de enseñanza no solo de las ciencias, si no de todas las áreas de formación de las personas; Por lo cual, este tipo de apuestas metodológicas invita a docentes y estudiantes a la apropiación de la investigación, convirtiendo este proceso en una estrategia pedagógica que busca dar una mirada a la comprensión latinoamericana de ambiente, economía, política y cultura, donde se pueda entrar a una acción libertadora de las dinámicas eurocéntricas que brindan una mirada económica a la naturaleza apartando al ambiente de una postura sustentable como la que se brinda en el desarrollo del trabajo, propendiendo por un conjunto que relaciona la comprensión de un planeta como un ser vivo y una mejor vida para todos, donde se propicien procesos de enseñanza aprendizaje reales para los estudiantes.

Para terminar y a modo de colofón se invita a los profesores de ciencias a llevar una formación artística a los diferentes espacios educativos que sea desde las habilidades y curiosidades de las estudiantes permite de una manera lúdico-recreativa transformar aquellas prácticas educativas con 
Bio-grafía. Escritos sobre la Biología y su Enseñanza. ISSN 2027-1034

Número Extraordinario. p.p. 309-316

\begin{abstract}
Memorias del Primer encuentro ambiental Universidad, ambiente y sustentabilidad: experiencias y prácticas.
\end{abstract}

carácter tradicional, que se encuentran fuera del contexto de las comunidades. Esto se encuentra relacionado a entender al ser humano como parte de una sociedad, en la que se debe compartir y entender a los demás, y a esta misma como parte de la naturaleza que es inherente para cada ser vivo, donde el accionar del sujeto debe propender por mantener un equilibrio armónico con todos los aspectos de la vida, enfocado a solucionar las problemáticas propias de sus realidades inmediatas.

\title{
BIBLIOGRAFÍA
}

Barrera, C. (2011). Los productos naturales como medio para promover el pensamiento crítico en ciencias. Investigación PPDQ (048), Bogotá.

Dieleman, H., \& Juárez, M. (Abril de 2008). ¿Cómo se puede diseñar educación para la sustentabilidad? Revista Internacional Contaminación Ambiental, 3(24), 131-147.

Gallopín, G. (mayo de 2003). Sostenibilidad y desarrollo Sostenible: Un enfoque sistématico. CEPAL-SERIE Medio ambiente y desarrollo, 146. Santiago de Chile.

Jiménez, M. (2009). El regreso de la química cotidiana ¿regresión o innovación? ENSEÑANZA DE LAS CIENCIAS, 257-272.

Longhi, A., \& Edson, S. (2012). Clubes de ciências: o que pensam os prfessores coordenadores sobre ciência, natureza da ciência e iniciacao científica numa rede municipal de ensino. Revista Electrónica de Enseñanza de las Ciencias, 11(3), 547-564.

Manjarrés, M. E., \& Villada, M. P. (2007). La investigacion como estrategia pedagogica. Programa Ondas de Colciencias .

Manjarres, M. M. (2014). I.E.P. una construcción ciudadana y demoscrática desde el sur. Programa Ondas de Colciencias.

Pierri, N. (2005). Historia del concepto de desarrollo sustentable. En G. Foladori, \& P. Naína, ¿Sustentabilidad? Desacuerdos sobre el desarrollo sustentable (págs. 27-81). México.

Rondón, D. \&. Gil (2015). Educación en Ciencias para la Sustentabilidad en la Escuela: Una propuesta para la enseñanza de la Química desde el Club de Ciencias. X Convención sobre Desarrollo Sostenible y 
Bio-grafía. Escritos sobre la Biología y su Enseñanza. ISSN 2027-1034

Número Extraordinario. p.p. 309-316

Memorias del Primer encuentro ambiental Universidad, ambiente y sustentabilidad: experiencias y prácticas.

Educación Ambiental. Habana, Cuba: Ministerio de Ambiente y Tecnología de Cuba

Rondón,D.. (13 de Mayo de 2015). Química cosmética como estrategia para la contextualización y enseñanza de las ciencias. Latin American Journal of Science Education. Obtenido de http://www.lajse.org/nov15/22074_Rondon_2015.pdf

Sauvé, L. (1996). Environmental Education and Sustainable Development: A Furthe Appraisal. Canadian Journal of Enviromental Education, 1, 734.

Sauvé, L. (2010). Educación científica y educación ambiental: un cruce fecundo. Enseñanza de las Ciencias, 28(1), 5-18.

UNESCO. (diciembre de 2002). Decenio de las Naciones Unidas de la Educación para el Desarrollo Sostenible 2005 - 2014. Obtenido de Decenio de las Naciones Unidas de la Educación para el Desarrollo Sostenible 2005 - 2014:

http://unesdoc.unesco.org/images/0014/001416/141629s.pdf 